Ebisu Ebisu

Études japonaises Études japonaises

49 | printemps-été 2013

De chose en fait : la question du milieu

\title{
Présences françaises à Okinawa : de Forcade (1844-1846) à Haguenauer (1930)
}

French Presence in Okinawa From Forcade (1844-1846) to Haguenauer (1930)

沖縄に滞在したフランス人たちーフォルカード（1844-1846年）からア グノエル（1930年）まで—

\section{Patrick Beillevaire}

\section{OpenEdition}

\section{Journals}

Édition électronique

URL : http://journals.openedition.org/ebisu/815

DOI : 10.4000/ebisu.815

ISSN : 2189-1893

Éditeur :

Institut français de recherche sur le Japon (UMIFRE 19 MAEE-CNRS), Maison franco-japonaise

\section{Édition imprimée}

Date de publication : 1 avril 2013

Pagination : 133-164

ISSN : 1340-3656

\section{Référence électronique}

Patrick Beillevaire, «Présences françaises à Okinawa : de Forcade (1844-1846) à Haguenauer (1930) », Ebisu [En ligne], 49 | printemps-été 2013, mis en ligne le 17 novembre 2014, consulté le 19 avril 2019. URL : http://journals.openedition.org/ebisu/815 ; DOI : 10.4000/ebisu.815 


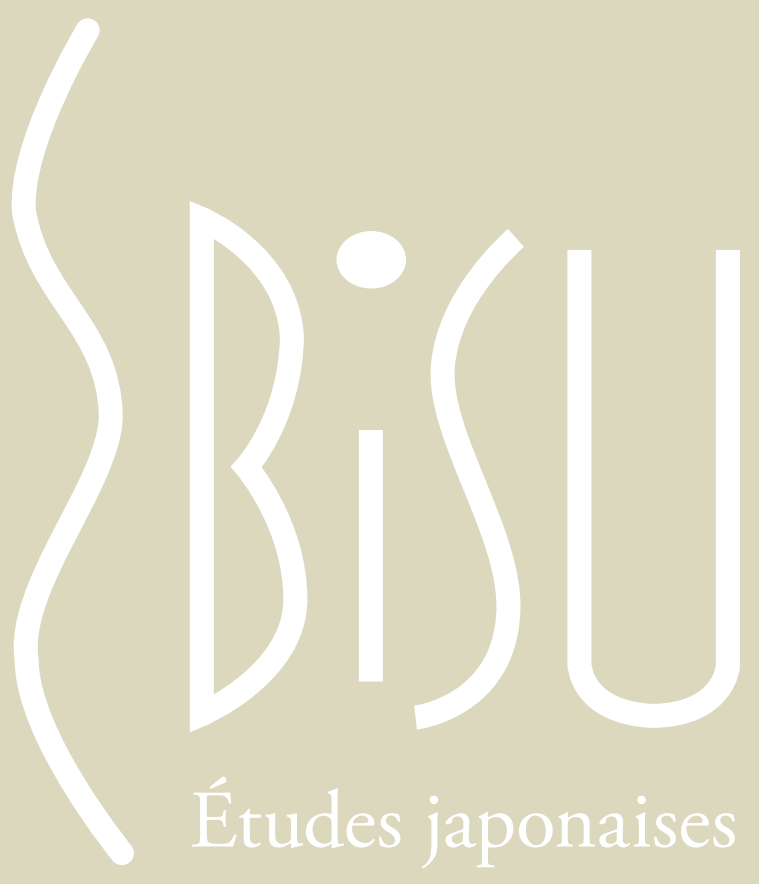

Dossier

De chose en fait : la question du milieu

Articles issus du colloque de Shin-Hirayu

Coordonné par Augustin BERQue

Varia | Nicolas Baumert - Peut-il exister des terroirs du saké ?

Conférences de la MFJ | François Macé - Le Kojiki, une Énéide longtemps oubliée ? | Patrick Beillevaire - Présences françaises à Okinawa : de Forcade (1844-1846) à Haguenauer (1930)

Livres à lire

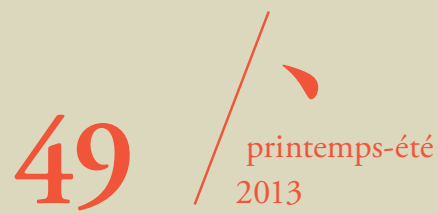




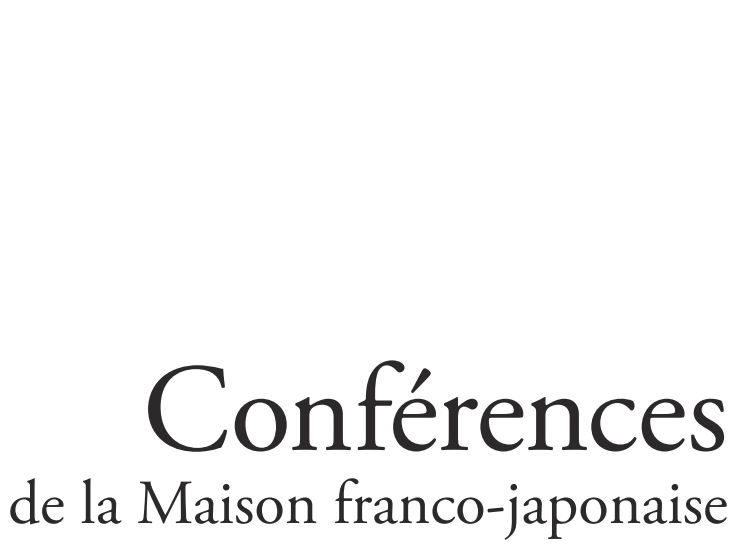




\title{
Présences françaises à Okinawa De Forcade (1844-1846) à Haguenauer (1930)
}

\author{
Patrick BEILLEVAIRE*
}

Au milieu du XIx ${ }^{e}$ siècle, à l'aube de son expansion coloniale, deux raisons conduisent la France à s'intéresser à l'île d'Okinawa. D'une part, elle apparaît à la fois comme un possible point d'appui pour sa marine en ExtrêmeOrient et comme une éventuelle voie d'accès au marché japonais. D'autre part, territoire du royaume des Ryūkyū 琉球王国, et dans la perspective de l'ouverture prochaine du Japon, elle est le seul lieu se rattachant peu ou prou à la sphère culturelle japonaise où la présence de prêtres catholiques ait quelque chance d'être acceptée.

L'intérêt de la France pour le royaume des Ryūkyū s'inscrit bien sûr dans le cadre plus large des rapports que les Européens, rejoints par les Américains, ont entretenus avec celui-ci. De la fin du $\mathrm{xvIII}^{\mathrm{e}}$ siècle aux années 1860, beaucoup d'événements jalonnent cette histoire, qui est aussi celle de la découverte progressive de la subordination du royaume au fief de Satsuma 薩摩藩. C'est une histoire bien documentée par des sources tant européennes que ryūkyū ou japonaises. Cette conférence se limite toutefois aux seuls Français, et en particulier à leurs contacts avec les autorités du royaume.

Ce texte est issu d'une conférence qui s'est donnée le 2 novembre 2012 à la MFJ.

* CNRS-Centre de recherches sur le Japon, EHESS. 
I.

Il me faut d'abord évoquer brièvement la connaissance que l'on avait des îles Ryūkyū avant qu'elles ne fassent l'objet de missions d'exploration. C'est en 1758 qu'a paru, dans la revue jésuite Lettres édifiantes et curieuses, la première étude savante sur la géographie, l'histoire et la culture de ces îles, jusque-là presque inconnues des Européens. Intitulée " Mémoire sur les îles que les Chinois appellent îles de Lieou-kieou » et accompagnée d'une carte, cette étude est l'œuvre d'un savant français de la mission jésuite de Pékin, Antoine Gaubil'. Elle s'appuie sur un rapport chinois, Zhōngshān chuánxin lù (Chūzan denshin-roku) 中山傅信録 ${ }^{2}$, rédigé par le vice-ambassadeur Xú Băoguāng (Jo Hokō) 徐葆光 qui séjourna huit mois à Okinawa en 1719 pour l'investiture du roi Shō Kei 尚敬. Dans ce mémoire, et plus encore dans sa correspondance, Gaubil donne à croire que le royaume des Ryūkyū demeure un État souverain, librement tributaire de la Chine, et qu'il serait possible de commercer avec le Japon par son intermédiaire. Son invasion par le fief de Satsuma en 1609, le pillage du palais royal et l'exil du roi Shō Nei 尚寧 à Kagoshima 鹿児島 sont bien mentionnés, mais comme des événements qui n’altérèrent pas l'indépendance du royaume. Attribuée à une trahison, la "disgrâce de Chang-ning [Shō Nei] augmenta sa réputation » et le fit admirer de tous pour «sa constance et la tranquillité de son esprit " dans l'épreuve. Finalement, " les Japonais, après deux ans de prison, le renvoyèrent avec honneur dans ses États ». L'écho qu'eurent le mémoire et la carte de Gaubil dans le milieu des cartographes et géographes amena bientôt les marines britannique et française à inscrire les îles

1. Traduction japonaise : "Shinajin ga Ryūkyū-shotō to yobu shotō ni tsuite no oboegaki, Pekin no Iezusu-kai senkyōshi Antoanu Gōbiru shi shirusu »シナ人が 琉球諸島と呼ぶ諸島についての覚書、北京のイエズス会宣教師アントアヌ・ゴービル師記す, Iezusu-kai shi Chügoku shokanshū イエズス会士中国書簡集, vol. 5, Tōyō bunko 東洋文庫 251, Heibonsha 平凡社, 1995 [1974] : 215-264.

2. "Rapport sur Chūzan ", d'après le nom de la principauté qui unifia politiquement l'île d'Okinawa au début du Xv' siècle, demeuré ensuite celui du royaume, officiellement appelé Ryūkyū-koku Chūzan-fu 琉球国中山府, "gouvernement de Chūzan du pays de Ryūkyū ». 
Ryūkyū, favorablement situées aux abords de la Chine et du Japon, sur la liste des terres à explorer ${ }^{3}$.

La première expédition qui passa par les îles Ryūkyū est celle de La Pérouse. Ses deux navires, L'Astrolabe et La Boussole, n'y firent qu'une brève halte, au matin du 4 mai 1787, à proximité de l'île de Yonaguni 与那国島 ${ }^{4}$. Les équipages purent néanmoins avoir des échanges amicaux avec les insulaires venus les aborder sur leurs pirogues. Dans son journal, La Pérouse note, se référant aussi à Gaubil, qu'il est " assez porté à croire " que dans " la grande isle de Likeu " (autrement dit Okinawa) les Européens « seraient reçus et trouveraient peut-être à y faire un commerce aussi avantageux qu'au Japon $^{5}$ ». Dix ans plus tard, en 1797, l'année où fut publié le Voyage de La Pérouse, cette impression favorable se trouva confirmée par le capitaine britannique Broughton qui, victime d'un naufrage sur les côtes de l'île de Miyako 宮古島, reçut de la population une aide généreuse et efficace.

Après l'intermède des guerres napoléoniennes, la Royal Navy visita par deux fois Okinawa, en 1816 et en 1827. Des navires marchands y abordèrent également. Peu à peu, il apparut que l'assistance empressée que l'on y prodiguait aux visiteurs n'était que le moyen d'écourter leur présence sur l'île. La simple évocation d'un possible accord commercial suscita un refus immédiat. Mais bientôt les Britanniques obtinrent de la Chine, par le traité de Nankin de 1842, la cession de Hongkong et l'ouverture de plusieurs ports, et leur attention s'éloigna d'autant des îles Ryūkyū.

3. Dès 1752, année où parvinrent en France le manuscrit et la carte de Gaubil, les géographes du roi Jean-Baptiste d'Anville et Philippe Buache republièrent des cartes de l'Asie orientale intégrant, telle quelle, celle de Gaubil. Jusqu'alors, les îles Ryūkyū restaient terra incognita pour les cartographes européens qui n'avaient connaissance d'aucun toponyme vernaculaire et en ignoraient tout du nombre comme des positions. Mis à part l'île d'Okinawa, dénommée " Grande Liuqiu » selon l'usage chinois, seules les îles du sud de l'archipel (Sakishima shotō 先島諸島) étaient grossièrement mentionnées sous l'appellation "îles des Rois mages » donnée par des navigateurs au Xvi ${ }^{e}$ siècle. C'est aussi la carte de Gaubil qui fit connaître en Europe l'existence des îles Senkaku 尖閣諸島 et leur usage comme jalon par les marins chinois et ryūkyū.

4. Appelée Kumi par La Pérouse sur la foi de la carte publiée par Gaubil, seule erreur véritable de cette carte sur laquelle figure bien, par ailleurs, Kumejima 久米島.

5. Le Voyage de Lapérouse, 1785-1788, Paris, Imprimerie nationale, 1985, tome II : 289-291. 
II.

La France, quant à elle, resta quasiment absente de l'Extrême-Orient jusque dans les années 1830. C'est en fait à partir de 1841, sous l'impulsion de François Guizot, ministre des Affaires étrangères et homme fort du gouvernement, que fut mise en œuvre une politique visant à rétablir une présence consulaire et navale en mer de Chine ${ }^{6}$. Lenvoi de la mission diplomatique dirigée par Théodose de Lagrené, qui allait signer avec la Chine le traité de Huangpu (Huángpǔ tiáoyuē 黄埔條約) le 24 octobre 1844, fut l'occasion de prendre contact avec le royaume des Ryūkyū. Il s'est agi, en réalité, d'une opération concertée au plus haut niveau du gouvernement entre Guizot et le supérieur de la Société des missions étrangères de Paris, laquelle venait de se voir attribuer par Rome les îles Ryūkyū avec la Corée et le Japon ${ }^{7}$. Sa mise à exécution par la Marine se fit à l'insu des Affaires étrangères et de Lagrené lui-même. Lorsqu'il en sera informé, seulement un an plus tard, par Qíying 者英, haut commissaire impérial délégué aux Affaires étrangères et signataire du traité avec la France, Lagrené ne pourra qu'exprimer à Guizot sa réprobation d'une démarche qui risquait de compromettre les relations nouées par la France avec la Chine ${ }^{8}$.

Dès avril 1844, l'amiral Jean-Baptiste Cécille, chef de la station navale formée pour la venue de l'ambassade, dépêcha à Okinawa le capitaine de frégate Eugène Fornier-Duplan sur L'Alcmène. Sa mission était double : d'une part, annoncer l'arrivée prochaine de Cécille en vue de la conclusion d'un traité d'amitié et de commerce avec le royaume, d'autre part, y déposer un missionnaire et veiller à ce qu'il soit bien accueilli. Pour ce dernier, le choix s'était porté sur un jeune prêtre assez ambitieux, Augustin Forcade,

6. Sur le sujet, on peut consulter l'excellente thèse d'Alexandre Allain, La France de Guizot et l'Extrême-Orient (1840-1848), École nationale des chartes, 1999.

7. Amédée Bocher, Aventures d'un missionnaire français aux îles Liou-Tcheou, 18441846, Paris, H. Richard, 1895 : 10. La proximité familiale de cet officier de marine avec Guizot donne du crédit à son témoignage, voir Allain, op. cit. : 64.

8. Louis Wei Tsing-sing, La Politique missionnaire de la France en Chine, 1842-1856, Paris, Nouvelles éditions latines, 1961 : 374-378. Lagrené lui-même avait toutefois souhaité inclure les îles Ryūkyū dans la liste des ports ouverts aux Français, mais cela lui avait été refusé par les autorités chinoises. 
qui avait pris l'initiative, par des voies qui restent encore à éclaircir, d'en appeler au Saint-Siège pour obtenir cette affectation ${ }^{9}$. Il était accompagné d'un catéchiste chinois, sorti de prison par Cécille, nommé Augustin Kō (Gāo) 高. Par le truchement de ce dernier, Fornier-Duplan s'entretint avec un prétendu gouverneur, Maezato uékata ${ }^{10}$ 真栄里親方, représentant Shuri 首里, le siège du pouvoir royal. Forcade et Kō furent présentés comme des interprètes officiels, placés sous la protection du roi de France, venus apprendre la langue japonaise pour être ensuite mis au service de l'amiral Cécille. On ignorait alors, et pour quelques années encore, que la langue parlée à Okinawa n'était pas compréhensible au Japon ${ }^{11}$. Par crainte de représailles, les autorités ryūkyū et le magistrat de Satsuma (zaiban bugyō 在番奉行) se résignèrent à accepter la présence des deux hommes.

Il est piquant de relever que dans son journal Fornier-Duplan se montre lui-même très critique du soutien apporté par la marine royale aux missionnaires, prétexte ensuite à une intervention militaire si un mauvais sort leur est fait ${ }^{12}$.

9. La démarche de Forcade (1816-1885) auprès de Rome, bien que jugée irrégulière et désapprouvée par Jean Dubois et Joseph Voisin, directeurs au séminaire des Missions étrangères, fut néanmoins avalisée, car la Marine faisait en même temps savoir qu'elle se chargerait de transporter le futur missionnaire à Okinawa. Guizot lui-même semble avoir cautionné le choix de Forcade. S'il est peu plausible que ce dernier ait alors rencontré le ministre, il bénéficia certainement auprès de lui du soutien personnel du supérieur du séminaire, Charles Langlois. Forcade prétendra plus tard que c'est à lui et non aux Missions étrangères que la congrégation De Propaganda Fide avait confié les îles Ryūkyū, mais il n’obtiendra pas gain de cause. Voir Archives des Missions étrangères de Paris (ci-après AMEP), vol. 44 : 889, et lettre commune de 1853 ; Wei Tsing-sing, op. cit. : 373.

10. Titre porté par les hommes de la haute aristocratie dont le rang venait juste après celui du roi $\bar{o}$ 王, des princes $\overline{o j} i$ 王子 ou des descendants des anciens seigneurs provinciaux aji ou anji 按司 dans la hiérarchie de l'État ryūkyū.

11. Le premier jour où il descendit à terre, le 28 avril 1844, Forcade fit demander plusieurs fois, par l'intermédiaire de Kō, " quelle était la langue qu'ils parlaient entre eux, si c'était une langue propre à leur île, si c'était la langue japonaise ", mais il n'obtint jamais de réponse (AMEP, vol. $568: 5$ ).

12. Bibliothèque municipale de Troyes, manuscrit 3181, Bénigne Eugène FornierDuplan, "Campagne en Chine de la corvette L'Alcmène, 1843, 4, 5 et 6. Seconde partie " : 16-17. 
Toujours est-il que, au début du mois de mai 1844, Forcade et Kō s’installèrent dans un petit monastère de l'école Shingon 真言宗, le Seigenji 聖現寺, situé au lieu-dit Ameku 天久 près du port de Tomari 泊村, à la périphérie nord de Naha 那覇. Je ne m'étendrai pas sur leurs conditions de vie. Les deux hommes demeurèrent libres de se déplacer, mais ils furent sans cesse surveillés, de jour comme de nuit. Les vivres leur étaient fournis gratis sans qu'il leur fût permis de s'approvisionner sur les marchés locaux. La tolérance de Satsuma, toujours attentif à cacher son influence, n'alla toutefois pas jusqu'à l'abandon des édits antichrétiens, et tout prosélytisme leur fut interdit. Avec l'aide d'officiers chargés de sa surveillance, Forcade parvint assez rapidement à confectionner " un petit dictionnaire de plus de six mille mots ", dont il se plaît à faire état dans une lettre d'août 1845. Cet ouvrage, qui serait un précieux document pour une langue sans écriture, n'a malheureusement pas été retrouvé. On sait cependant qu'il n’a pas eu le sort du journal du missionnaire, disparu en 1847 dans le désert d'Arabie avec ses bagages, puisque ses successeurs, dans la décennie suivante, en disposaient pour préparer leur séjour aux Ryūkyū $\bar{u}^{13}$.

Pour l'anecdote, lors de son débarquement Forcade étonna fort ses interlocuteurs en leur montrant les illustrations relatives à Okinawa du Voyage pittoresque autour du monde de Dumont d'Urville, ouvrage paru en 18341835. Ce récit de voyage fictif, souvent réédité, fait un tableau des plus idylliques et des plus romantiques de la société ryūkyū, véritable Arcadie, vestige de "l'âge d'or de l'humanité ". Il s'inspire étroitement des relations de voyage de Basil Hall, John M'Leod et Frederic Beechey venus à Okinawa,

13. Lettre de Forcade à Libois, AMEP vol. 568 : 33. Ogawa Tōru 小川徹, « Senkyōshi Forukādo to maboroshi no ryū-futsu jisho » 宣教師フォルカードと幻の琉仏辞書 (Le missionnaire Forcade et le dictionnaire fantôme ryūkyū-français), Iha Fuyū zenshū 伊波普猷 全集 (CEuvres complètes d'Iya Fuyū), vol. 5, Tokyo, Heibonsha, 1974, Geppō 月報 : 3-5. Le lexique fut recopié par Louis Furet lorsqu'il séjournait à la procure de Hongkong en 1854, AMEP, vol. 139 : 1313. Ce qui a été publié sous le titre Le Premier Missionnaire $d u$ Japon au xixe siècle (Lyon, Missions catholiques, 1885) n'est qu'un extrait du journal préparé par Forcade en vue d'une publication et envoyé de Manille en octobre 1846. Traduction japonaise par Nakajima Akiko 中島昭子 et Ogawa Sayuri 小川早百 合 : Forukādo shinpu no Ryükyū nikki : Bakumatsu nichifutsu köryüki フォルカード神父 の琉球日記・幕末日仏交流記, Tokyo, Chūō kōronsha 中央公論社 (Chūkō bunko 中公文 庫), 1993. Sur la perte du journal, voir Edmont Marbot, Vie de Monseigneur Forcade, archevêque d'Aix, Arles et Embrun, Aix, Achille Makaire, et Paris, Lesort, 1886 : 163. 


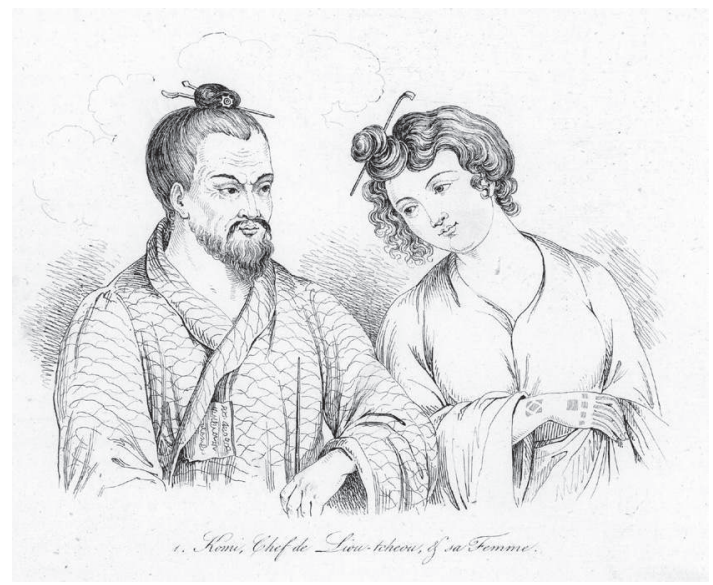

Fig. 1. Un couple romantique. Illustration du Voyage pittoresque autour du monde de Dumont d'Urville (1834-1835), composée à partir de deux figures séparées accompagnant le récit de voyage de Frederic Beechey (1831).

les deux premiers en 1816 , le troisième en $1827^{14}$. Les illustrations sont également tirées de leurs ouvrages (fig. 1). Grands succès de librairie, les récits de Hall et de M'Leod décrivent un peuple avenant et affable, ignorant la monnaie, le crime, les armes et la guerre. Les mouvements pacifistes américains et britanniques furent d'ailleurs prompts à ériger en modèle ce peuple exceptionnel ${ }^{15}$.

Il est d'autre part un épisode drolatique du voyage de Basil Hall - épisode bien connu à Okinawa, rapporté seulement dans l'édition populaire de son

14. Basil Hall, Account of a Voyage of Discovery to the West Coast of Corea and the Great Loo-Choo Island, Londres, John Murray, 1818 ; John M'Leod, Narrative of a Voyage in His Majesty's Late Ship Alceste to the Yellow Sea, Londres, John Murray, 1817 ; Frederic W. Beechey, Narrative of a Voyage to the Pacific and Beering's Strait, Londres, Henry Colburn et Richard Bentley, 1831, 2 vol.

15. Teruya Yoshihiko 照屋善彦, "Ryūkyū and Its Role in Western Thought : EuroAmerican Peace Movements in the Early Nineteenth Century ", Ryükyü in World History, Josef Kreiner (ed.), Bonn, Bier'sche Verlagsanstalt, 2001 : 261-278. 
récit de voyage ${ }^{16}$ - qui concerne la France, en la personne de l'empereur Napoléon I ${ }^{\text {er }}$. Alors qu'il regagnait l'Angleterre sur la Lyra, Hall, dont le père avait été un condisciple du jeune Napoléon au collège militaire de Brienne, rendit visite à l'empereur déchu dans son exil de Sainte-Hélène. Napoléon lui fit bon accueil et se montra très curieux de ce qu'il avait pu apprendre au cours de son périple sur les peuples de l'Extrême-Orient. Lorsque Hall en vint à lui parler de ce qu'il avait observé à Okinawa, Napoléon entra dans un état de grande excitation. La description de la scène le montre véhément, le poing serré, dire son incrédulité à l'idée qu'un peuple pourrait ne connaître ni la guerre, ni les armes, pas même des poignards! Aujourd'hui encore, les récits de Hall et de M'Leod continuent de nourrir le mythe du pacifisme ancestral des habitants d'Okinawa.

Pour en revenir à Forcade, celui-ci donnait foi à la description faite dans le livre de Dumont d'Urville, comme le montre une lettre écrite à son arrivée ${ }^{17}$. Il déchanta vite, cependant, et n'eut ensuite de cesse de protester contre l'espionnage auquel il était soumis, en laissant entendre que le courroux qu'en concevrait l'amiral Cécille aurait de graves conséquences pour ses hôtes.

III.

Il lui fallut pourtant patienter deux ans avant que l'amiral n'arrive. L'ambassade de Lagrené, puis la tentative de conquête de l'île de Basilan, dans l'archipel philippin des Sulu, le retinrent en effet plus longtemps que prévu. Après l'échec de Basilan, dû à des raisons plus diplomatiques que militaires, c'est Okinawa qui semblait le mieux correspondre aux critères énoncés par Guizot pour le choix d'un point d'appui comparable au Hongkong des Britanniques ${ }^{18}$. Un premier navire, la corvette La Sabine,

16. Basil Hall, Voyage to Loo-Choo, and Other Places in the Eastern Seas in the Year 1816, Edinburgh, Archibald Constable, 1826 : 310-318.

17. "M. Duplan vous dira combien est bon le peuple de Lieou-Kieou; c'est incroyable, il n'y a rien d'exagéré dans les récits qui en ont été faits. Nous ne pouvons en revenir, nous qui avons vu les choses de nos yeux. Les mandarins eux-mêmes ont un grand fond de bonté. " (AMEP, vol. 569 : 2, lettre au procureur Napoléon Libois du 5 mai 1844).

18. Voir l'introduction de Guizot à la traduction française du livre de Laurence Oliphant, La Chine et le Japon. Mission du Comte d'Elgin pendant les années 1857, 1858 


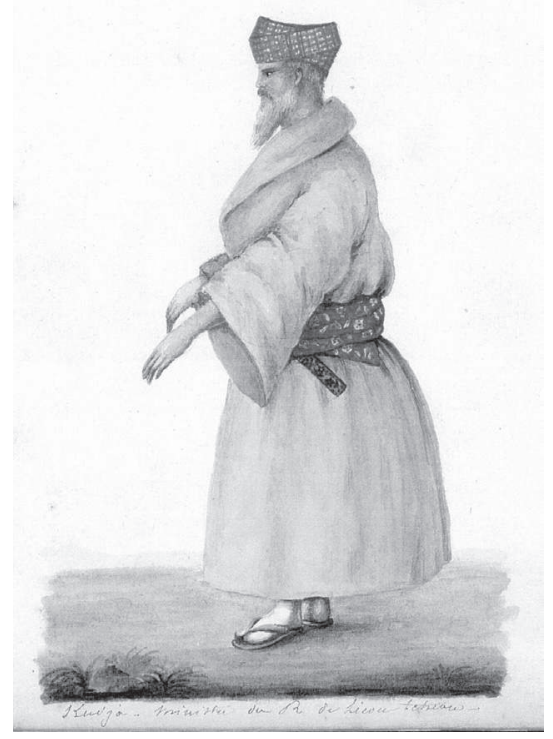

Fig. 2. Kuja aji, le représentant du gouvernement de Shuri à la négociation d'Unten avec l'amiral Cécille (coll. Michel Barthes).

aux ordres du capitaine de vaisseau Nicolas Guérin, jeta l'ancre à Naha le 2 mai 1846 avec à son bord un nouveau missionnaire, Pierre Leturdu. Un mois plus tard, après avoir effectué des relevés sur la côte ouest de l'île, Guérin - sourd à la prière des autorités de n'en rien faire ${ }^{19}$ - appareillait pour la baie d'Unten 運天湾, sur le versant nord de la presqu'île de Motobu 本部半島, lieu de concentration choisi par Cécille pour son escadre. Deux autres navires, le vaisseau amiral $L a$ Cléopâtre et $L a$ Victorieuse, ne tardèrent

et 1859, Paris, Michel Lévy, 1860 : x-xi.

19. Prière exprimée notamment dans une lettre en date du 27 mai 1846 adressée au commandant Guérin par le fusei taifu 布政大夫 Shō Eiho 尚 (ou 向) 永保, pseudonyme de Zakimi Seifu 座喜味盛普 (ou Mō Tatsutoku 毛達徳). 
pas à l'y rejoindre. Forcade eut la chance de pouvoir se hisser à bord de $L a$ Cléopâtre lors de son passage devant Naha.

La baie d'Unten, explorée en 1816 par les Britanniques, est certes un excellent havre, mais elle est située à une soixantaine de kilomètres de Shuri, ce qui n'en faisait pas le lieu le mieux approprié pour mener des négociations. Le 8 juin, un jour après son arrivée, Cécille fit savoir au gouverneur de la région qu'il souhaitait s'entretenir avec un "grand mandarin » de la capitale d'un rang égal au sien. Huit jours plus tard arriva de Shuri un homme appelé Kuja 古謝, paré du titre de sōri daijin 総理大臣, «Premier ministre ", ou, comme cela fut interprété en français, de " ministre général de la ville de Choui (Shuri) " (fig. 2). Il faut savoir que les vrais responsables du royaume ne se montraient jamais aux visiteurs occidentaux. Des hommes de paille, d'un rang comparable, se substituaient à eux en se présentant sous un pseudonyme (gimei 偽名) chinois et avec un titre fictif. Les aristocrates possédaient en plus de leur nom ryūkyū un "nom chinois ", karana $\bar{a}$ 唐名, auquel s'appliquait une lecture japonaise ou ryūkyū-japonaise. L'emploi d'un pseudonyme ryūkyū, tel Kuja dans le cas présent, est exceptionnel. Je ne peux entrer ici dans le détail de cette question qui n'avait pas reçu d'attention particulière jusqu'aux recherches assez récentes de l'historien Dana Masayuki 田名真之 ${ }^{20}$. Kuja, qui avait le rang d'aji 按司 ${ }^{21}$, s'appelait ainsi Kunigami Seishū 国頭正秀, encore qu'un doute puisse ici subsister sur l'identité réelle du personnage. Dans ses lettres, il utilise le pseudonyme " chinois» Shō Teichū 尚廷柱.

Les négociations entre l'amiral Cécille, conseillé par un Forcade très vindicatif, et le représentant de Shuri durèrent plus d'un mois, jusqu'à la mijuillet 1846. Entre-temps, deux marins français moururent de maladie et furent enterrés sur l'île de Yagadji 屋我地島, en bord de mer, où leur tombe est toujours visible ${ }^{22}$ (fig. 3). Satsuma, dont la mainmise sur les Ryūkyū

20. “Ōfu no ikokusen geisetsu taisei » 王府の異国船迎接体制 (Le système d'accueil des navires étrangers du gouvernement royal), Ryūkyū ōkoku hyōjōsho monjo 琉球王国評定 所文書 (Documents du conseil exécutif du royaume des Ryūkyū), Urasoe 浦添, Urasoe shiritsu toshokan 浦添市立図書館, vol. 14, 1998 : 5-43.

21. Titre des anciens seigneurs régionaux.

22. Jacques Sallus, cuisinier sur La Victorieuse, et François Charles Guitart, second maître armurier sur La Cléopâtre. Leur tombe commune est connue sous l'appellation Oranda baka オランダ墓 (« tombe des Hollandais »). 

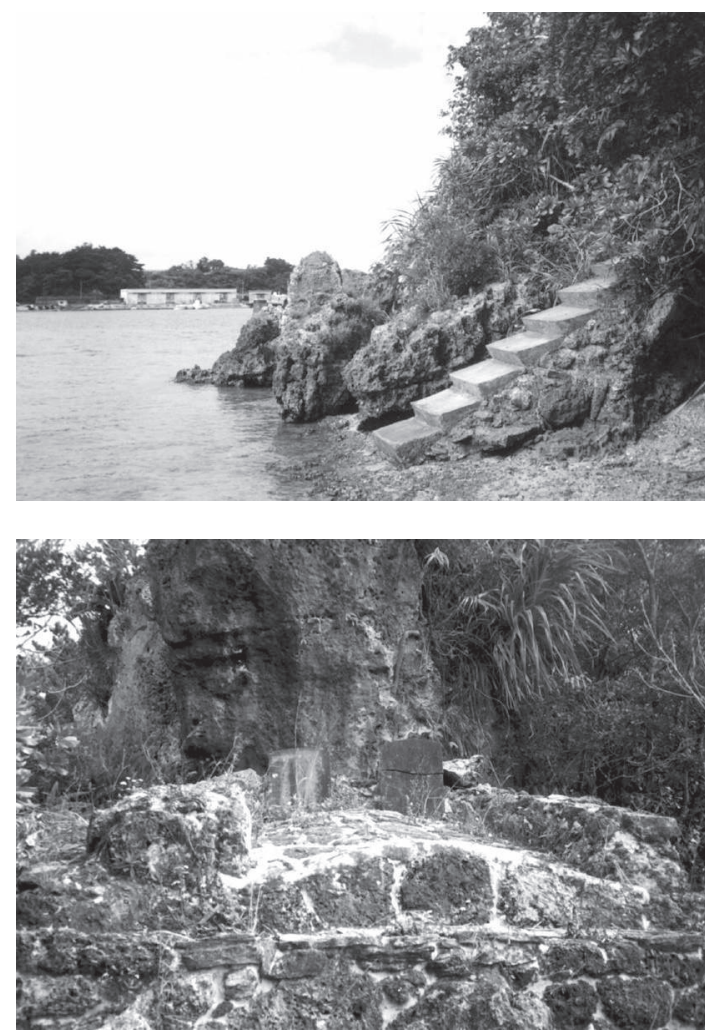

Fig. 3. Tombe de deux marins français morts en juin 1846, Jacques Sallus et François Guitart, sur l'île de Yagaji (photos P. Beillevaire, 1989).

restait ignorée de Cécille, fut tenu régulièrement informé de la situation. Les rencontres eurent lieu dans le village de Kami-Unten (rk. Ui-Untin) 上運天 ou sur La Cléopâtre. Un aller et retour de Kuja à Shuri les interrompit pendant deux semaines. Chaque partie consigna ses arguments dans des lettres écrites en chinois ${ }^{23}$ (fig. 4). L'amiral proposait au royaume des Ryūkyū

23. AMEP, vol. 568 : 95-210, passim, et vol. 184, pour les originaux des lettres de Kuja ; Archives nationales, MAR BB/4/637, lettre de Cécille au ministre de la Marine 
un traité d'amitié et de commerce en bonne et due forme qui lui aurait assuré non seulement la protection bienveillante de la France, dont il vanta tout à la fois la puissance et l'attachement à la paix, mais aussi un essor économique lui permettant de recouvrer sa prospérité d'antan, à l'instar, expliqua-t-il, de petites nations maritimes européennes comme le Portugal, la Hollande ou l'ancienne Venise. L'ouverture récente de la Chine fut bien évidemment donnée en exemple. Mais l'insistance et l'attitude ferme, voire cassante, de Cécille n’y purent rien : "Son Excellence Kuja » et le gouvernement de Shuri s'obstinèrent, en des termes d'une grande humilité, à plaider " pour être dispensés de faire un traité de commerce avec la France ». En substance, la partie ryūkyū arguait de la trop grande pauvreté du royaume pour décliner l'offre de négoce, sa survie ne dépendant que de la Chine et, plus encore, de Tokara 吐噶喇島 ${ }^{24}$, un pays que l'on ne cacha pas être luimême très lié au Japon. Tout commerce avec les Européens, précisa-t-on, aurait eu pour effet immédiat la cessation des échanges avec Tokara, ce qui pour le royaume aurait signifié famine et ruine.

C'est le nom de ce minuscule archipel de Tokara, encore inconnu des Européens, qui était invoqué depuis 1683, devant les Chinois puis les Européens, pour masquer la domination de Satsuma et les relations du royaume avec le Japon, ou simplement pour indiquer aux visiteurs la provenance des navires de style japonais stationnés dans le port de Naha. Cécille s'employa alors à souligner la contradiction qu'il y avait entre l'affirmation de pauvreté et l'évidente prospérité du commerce que le royaume entretenait avec la Chine ; sans détours, il suggéra même à ses interlocuteurs de s'émanciper d'un Japon qui, via Tokara, les tenait ainsi à sa merci comme ils le prétendaient. Mais rien n'y fit. Il dut donc se contenter de leur faire savoir que leur refus et les arguments qui le déterminaient seraient portés à la connaissance du roi Louis-Philippe, élevé au rang " d'empereur des Français " pour ne pas amoindrir son prestige face aux monarques chinois et japonais : c'est lui qui aviserait sur la suite à donner à l'affaire, et il leur communiquerait sa décision dès qu'il en serait informé, c'est-à-dire, prévint-il, pas avant une année.

du 12 octobre 1846 et annexes, ff. 379-423.

24. Aussi appelé Takara ou Takara-jima 宝島, littéralement "l'île du trésor », nom d'une des îles composant cet archipel. 


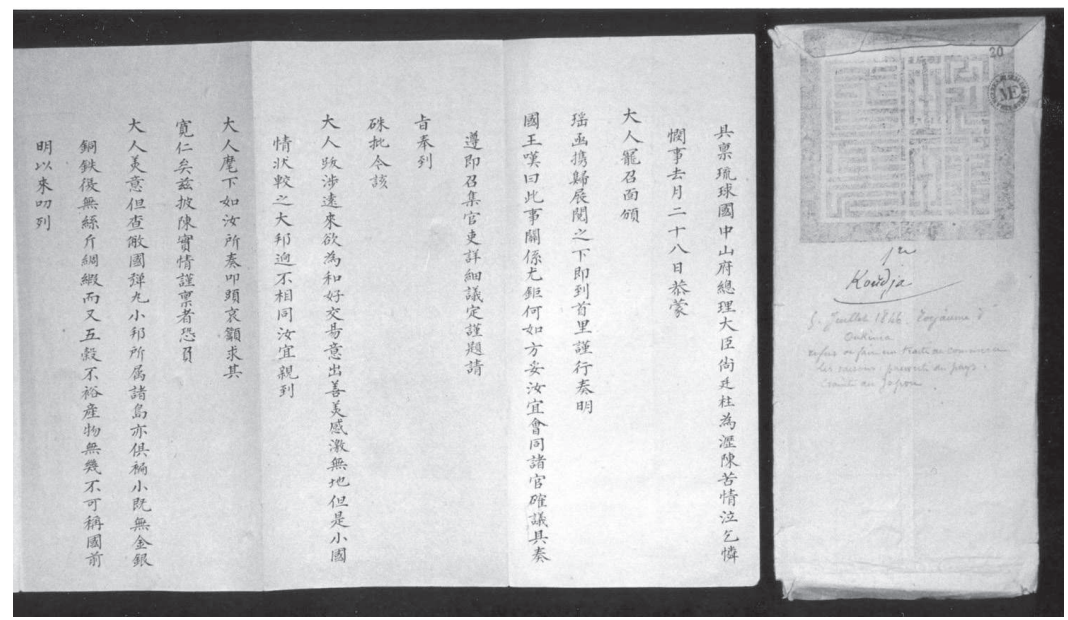

Fig. 4. Première lettre de Kuja remise à l'amiral Cécille le 5 juillet 1846 (AMEP).

Finalement, au terme des négociations, Cécille obtint la promesse orale que les missionnaires ne seraient plus surveillés et qu'il leur serait procuré des livres et des maîtres pour apprendre le japonais. On les autoriserait aussi, lui assura-t-on, à acheter eux-mêmes les denrées dont ils avaient besoin. Dans un rapport qu'il rédige en février 1847 à l'attention du commandant Lapierre, son successeur à la tête de la station navale, Cécille aborde la question du projet de commerce pour avouer que la connaissance qu'il a acquise des rapports qu'entretient le royaume des Ryūkyū avec la Chine et surtout avec le Japon lui a fait perdre ses "illusions $»^{25}$. Il explique que son intention initiale était d'ouvrir le marché japonais aux produits français en commissionnant des marchands d'Okinawa qu'il supposait avoir libre accès à ce marché. Mais, au fil des négociations, il en était venu à comprendre que les échanges commerciaux entre le royaume et le Japon étaient aussi strictement contingentés que ceux du Japon avec les Hollandais à Nagasaki. La perspective d'un commerce limité au seul royaume des Ryūkyū faisait perdre, à ses yeux, tout intérêt à un traité. Par ailleurs, Cécille n’ignorait pas

25 AMEP, vol. 568 : 525-535. 
que le gouvernement des Ryūkyū s'était plaint auprès du vice-roi du Fújiàn 福建 de la présence du prêtre Forcade et de son acolyte chinois, et que cette plainte avait été portée par Qíying à la connaissance de Lagrené, et par ce dernier à celle de Guizot. Il devait donc maintenant tenir compte de l'inquiétude des autorités chinoises comme de celle de la diplomatie française et se garder de nuire au traité conclu avec la Chine par une intervention trop insistante à Okinawa.

\section{IV.}

La démarche de Cécille à Okinawa ne fut cependant pas sans retentissement $\mathrm{au}$ Japon $^{26}$. Satsuma était d'ordinaire très discret sur tout ce qui concernait les îles Ryūkyū. Mais, cette fois, l'événement parut trop sérieux pour ne pas en informer rapidement Edo. Zusho Hirosato 調所広郷 (ou Shōzaemon 笑左衛門), habile responsable des finances du fief, fut chargé de rédiger un rapport à l'attention du rōju 老中 Abe Masahiro 阿部正弘, le ministre le plus influent du bakufu 幕府. Il y expliquait que le Japon n’était pas en position de force aux Ryūkyū en raison des liens du royaume avec la Chine et de la reconnaissance de ceux-ci par les Occidentaux. Aussi préconisaitil d'autoriser les Français à commercer à Okinawa s'ils maintenaient leur pression, afin d'éviter un affrontement militaire et de gagner du temps pour renforcer les défenses du pays. Abe Masahiro demanda alors à son conseiller pour les affaires étrangères, le ómetsuke 大目付 Tsutsui Masanori 筒井 政憲, de prendre discrètement contact avec Shimazu Nariakira 島津斉彬, l'héritier présomptif de Satsuma, qui résidait à Edo. Nariakira était à la fois très au fait des questions de défense et intéressé depuis son enfance par les pays européens, dont il n'ignorait bien sûr pas la supériorité navale et militaire. Considérant le royaume des Ryūkyū comme un "han (fief) extérieur" (gaihan 外藩), il se rangea aux vues de Zusho et conseilla un

26. L'étude la plus complète sur cet épisode est celle d’Ikuta Sumie 生田澄江, "Bakumatsu ni okeru Furansu kantai no Ryūkyū raikō to Satsu-Ryū kankei » 幕末に おけるフランス艦隊の琉球来航と薩琉関係 (La venue aux Ryūkyū à la fin du bakufu d'une escadre française et les relations entre Satsuma et les Ryūkyū), Okinawa bunka kenkyū 沖縄文化研究, vol. 19, 1992 : 1-93. 
assouplissement de la politique de fermeture du pays. Abe Masahiro, qui tenait Nariakira en haute estime, endossa cette position et en informa aussitôt le shōgun qui lui donna son aval. Le $1^{\text {er }}$ jour du $6^{\mathrm{e}}$ mois de la $3^{\mathrm{e}}$ année de l'ère Kōka 弘化 (le 23 juillet 1846), Tokugawa Ieyoshi 徳川家慶 reçut en audience privée Shimazu Narioki 島津斉興, daimyō de Satsuma, et son fils Nariakira. Il s'en remit à eux, en termes cordiaux, pour conduire l'affaire au mieux des intérêts du pays. Nariakira se hâta ensuite de gagner Satsuma, où, appuyé par Zusho, il prit rapidement des mesures financières et matérielles pour pouvoir répondre à la demande des Français ${ }^{27}$. Mais ceux-ci avaient quitté Okinawa et leur demande devait rester sans lendemain.

Quatre ans plus tard, dans un contexte de grave crise successorale au sein du fief de Satsuma, Shimazu Nariakira révélera à Abe Masahiro que son père, Narioki, et Zusho avaient considérablement menti sur le nombre de soldats envoyés en renfort à Okinawa après la visite de Fornier-Duplan, en 1844. Zusho fut contraint de se suicider, et Narioki de démissionner au profit de son fils Nariakira.

Forcade quitta Okinawa avec l'amiral Cécille. L'escadre se rendit ensuite à Nagasaki, où aucun Français ne put débarquer, puis sur les côtes de la Corée. Forcade prévoyait de retourner à Okinawa lorsqu'il apprit en Chine qu'il venait d'être nommé évêque du Japon, un pays où il ne poserait cependant jamais le pied. En 1847, il éprouva un vif dépit en apprenant d'un naufragé japonais que la langue parlée à Okinawa était incompréhensible au Japon. Mais bientôt, dans un contexte tendu, il abandonna les Missions étrangères et poursuivit sa carrière loin de l'Asie, en Guadeloupe, puis dans la France métropolitaine.

Leturdu remplaça donc Forcade au Seigenji. Il fut rejoint le 15 septembre 1846 par Mathieu Adnet, transporté sur La Victorieuse commandée par le capitaine de corvette Rigault de Genouilly. Leurs conditions de vie ne différèrent guère de celles de Forcade, excepté les " trois maîtres de langue ", peu motivés semble-t-il, que le gouvernement mit à leur service pour les

27. Ikuta, op. cit. : 66-71 ; Kuroda Yasuo 黒田安雄, “Kōka-ki no Ryūkyū gaikō jiken to Satsuma-han " 弘化期の琉球外交事件と薩摩藩 (Le fief de Satsuma et l'incident de politique étrangère aux Ryūkyū durant l'ère Kōka), Kaikoku to kindaika 開国と近 代化 (Ouverture du pays et modernisation), Nakamura Tadashi 中村質 (dir.), Tokyo, Yoshikawa kōbunkan 吉川弘文館, 1997 : 124-126. 
aider à apprendre le chinois et quelques notions de japonais. Pour ce qui est de la surveillance, elle ne diminua pas et leurs protestations restèrent vaines. Il leur arriva même d'être molestés par la police lorsqu'ils voulurent se joindre au cortège organisé pour les funérailles du roi Shō Iku 尚育 en octobre 1847. Le $1^{\text {er }}$ juillet 1848, Adnet mourut au Seigenji, probablement de la tuberculose. Il fut inhumé près du rivage, dans ce qui est aujourd'hui appelé le « cimetière des étrangers de Tomari » (Tomari gaijin bochi 泊外人 墓地), où reposait déjà un médecin de La Sabine, Jules Galland. Sa tombe a été reconstruite vers 1965 à l'initiative de catholiques américains (fig. 5). Pour la circonstance, Leturdu reçut de touchants messages de condoléances de la part des autorités de Shuri. Celles-ci dépêchèrent trois officiers qui s'associèrent à lui, "à la tête d'un nombreux cortège, tous en habits blancs ", pour la mise en terre de son confrère ${ }^{28}$. Il s'opposa cependant à ce que l'on vienne « sacrifier » sur sa tombe.
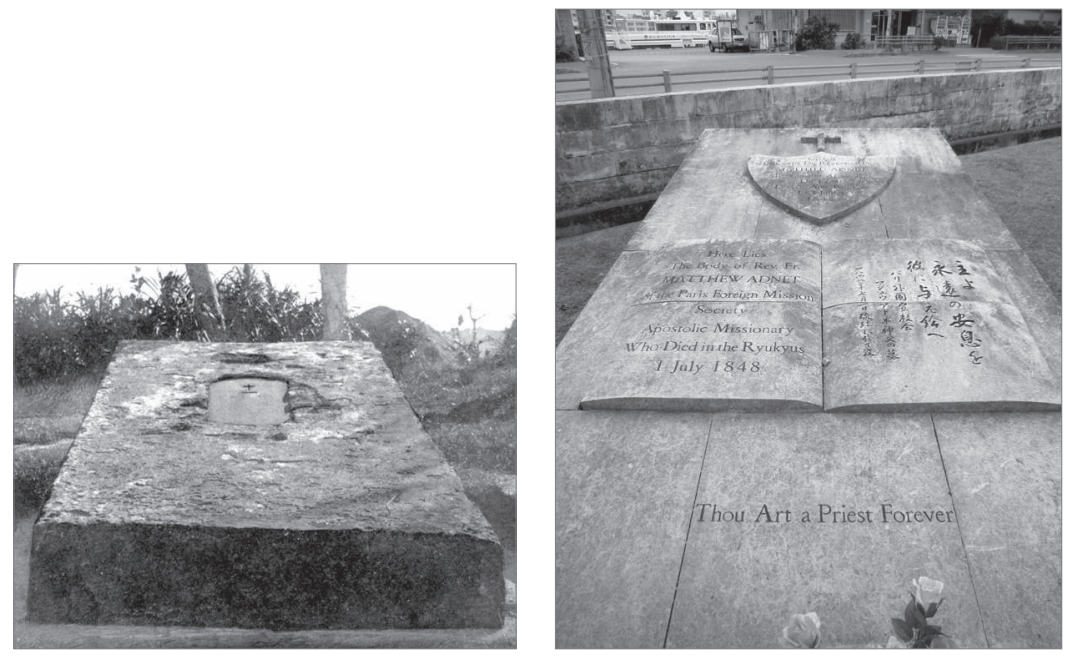

Fig. 5. Tombe de Mathieu Adnet à Tomari, hier et aujourd'hui (AMEP et photo P. Beillevaire).

28. AMEP, vol. $568: 525-535$. 
Deux mois plus tard, à la fin du mois d'août 1848, Leturdu était ramené en Chine où il poursuivit ses activités missionnaires. Sur son séjour à Okinawa, il a laissé un curieux rapport, bien informé sur la culture locale, en particulier sur les croyances populaires, que l'on peut à bon droit qualifier d'ethnographique ${ }^{29}$. Le capitaine de corvette Jurien de la Gravière, venu le rechercher sur La Bayonnaise, a, pour sa part, publié un récit très vivant de sa promenade dans Naha et Shuri ${ }^{30}$.

\section{V.}

Jusqu'en février 1855, il n'y eut plus de Français à Okinawa. Un missionnaire-médecin protestant britannique, affilié à l'Église d'Angleterre, Bernard Jean Bettelheim ${ }^{31}$, s'était lui aussi invité à Okinawa en 1846. Il en repartit avec l'escadre du commodore Perry lorsque celui-ci, après avoir utilisé Okinawa comme base arrière pour sa mission au Japon, y revint une dernière fois en juillet 1854 pour signer une convention avec le royaume des Ryūkyū. Le 26 février 1855, trois nouveaux prêtres, Prudence Girard, Eugène Mermet et Louis Furet, débarquèrent à Okinawa. Cette fois, les missionnaires ne purent bénéficier d'un transport gratuit sur un navire de la marine nationale et ils eurent à payer le capitaine d'un navire marchand, Le Lion, pour qu'il se déroute vers Okinawa. Comme leurs prédécesseurs, ils furent logés au Seigenji à Tomari.

29. AMEP, vol. 568 : 511-575. Publié sous le titre "Rapport sur Liou-Kiou " dans P. Beillevaire (dir.), Ryūkyū Studies to 1854. Western Encounter Part 1, Richmond, Curzon Press, et Tokyo, Edition Synapse, 2000, vol. 5. P. Beillevaire, « Heavenly Affinities and Discrepancies: Fr. Leturdu's early ethnographic account of Okinawa (1846-48) », in Religion in Japan. Arrows to Heaven and Earth, P. F. Kornicki et I. J. McMullen (dir.), Cambridge, Cambridge U.P., 1996 : 156-178.

30. Jean-Baptiste Edmond Jurien de la Gravière, Voyage en Chine et dans les mers et archipels de cet empire pendant les années 1847-1848-1849-1850, Paris, Charpentier, 1854, vol. $1: 212-248$.

31. Juif d'origine hongroise (né à Presbourg), converti par des missionnaires anglicans et naturalisé britannique, il fut le premier des deux missionnaires recrutés par la Loochoo Naval Mission fondée par Herbert Clifford, un des officiers qui accompagnaient Basil Hall. Il contribua à l'introduction de la vaccination antivariolique et traduisit en langue ryūkyū plusieurs livres du Nouveau Testament. 


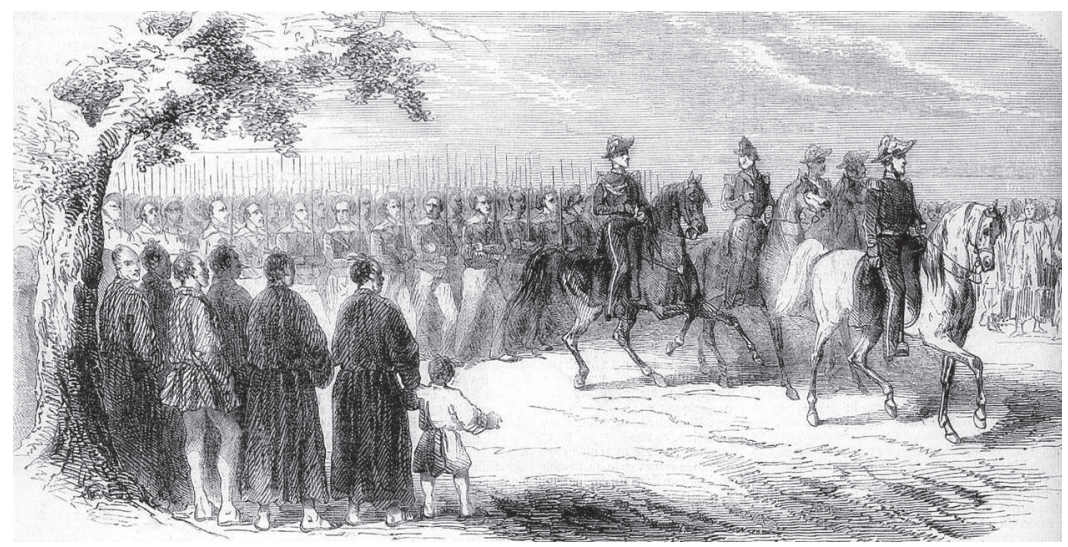

Fig. 6. Débarquement de l'amiral Guérin à Tomari en novembre 1855 (T. Aubé, L'Illustration, 15 mars 1856).

À Paris, les ministères des Affaires étrangères et de la Marine suivaient de près les mouvements des marines britannique et américaine. Ayant eu connaissance des avantages concrets déjà obtenus par le commodore Perry aux Ryūkyū $\bar{u}^{32}$, le ministre de la Marine et des Colonies demanda, dès juin 1854, au commandant de la station navale de la mer de Chine d'en obtenir de semblables pour la France. Mais l'entrée en guerre contre la Russie - ce que l'histoire retient sous le nom de guerre de Crimée - mobilisa alors les navires français de la mer de Chine pour la traque des navires russes, du nord du Japon au Kamchatka. Ce n'est donc pas avant novembre 1855 que Nicolas Guérin, promu contre-amiral, put rassembler une escadre de trois bâtiments, La Virginie, La Sybille et Le Colbert, pour se rendre à Okinawa. Il y avait à leur bord quinze cents hommes au total, dont plus d'une centaine de Chinois. Décidé à faire montre de force, l'amiral débarqua en paradant à cheval à la tête de ses troupes ${ }^{33}$ (fig. 6). Les officiels chargés de le recevoir, toujours des substituts aux autorités réelles, se montrèrent malgré

32. L'établissement d'un dépôt de charbon et le stationnement de soldats.

33. La visite de l'amiral Guérin à Okinawa est relatée par Théophile Aubé dans un article accompagné de huit lithographies, dont une montrant son débarquement à la tête 
tout peu enclins à signer un accord. L'amiral Guérin se persuada bientôt qu'un représentant du Japon, d'Edo plutôt que de Satsuma, était présent dans le bâtiment où se déroulaient les négociations - l'école de Wakasa 若狭学校, un quartier de Naha -, auprès duquel ses interlocuteurs allaient prendre leurs instructions ${ }^{34}$. Finalement, au terme de six rencontres étalées sur deux semaines, lassé par les propos dilatoires, l'amiral Guérin fit cerner le bâtiment par une quarantaine de fusiliers. Forçant alors les dignitaires ryūkyū à sortir dans le jardin, il menaça de les passer par le fil de l'épée ${ }^{35}$. La démonstration fut comprise, et trois jours plus tard, le 24 novembre 1855 , une convention comportant onze articles rédigée en français et en chinois, appelée en japonais jōyaku 条約, ou " traité ", était signée et scellée "en attendant la conclusion d'un traité plus complet " ${ }^{36}$ (fig. 7). Cette convention est calquée sur le compact conclu par Perry, avec de minimes ajouts. Le droit d'acheter ou de louer terrains, maisons ou bateaux ayant été refusé avec opiniâtreté par le gouvernement ryūkyū, celui-ci avait l'obligation d'en fournir aux Français, à leur convenance. Un terrain était concédé à proximité du débarcadère de Tomari pour éventuellement y établir un dépôt de charbon et y édifier des bâtiments administratifs.

N'oublions pas que malgré le traité d'amitié conclu à Kanagawa par les États-Unis (Nichibei washin jōyaku 日米和親条約), l'évolution des relations

de ses troupes : "L'expédition de l'Indo-Chine. Macao (Chine), 11 décembre 1855 ", L'Illustration, 15 mars $1856: 167-170$.

34. "Pendant toutes les négociations, bien que les négociateurs fussent véritablement les plus hauts dignitaires du royaume, rien n'a été consenti qu'après avoir été approuvé par un personnage caché dans une chambre voisine et qui dirigeait réellement les volontés des négociateurs liou-tchouans. Quelle était donc cette autorité mystérieuse ? Je présume, Monsieur le ministre, que Liou-tchou n'est qu'une province japonaise régie par un proconsul envoyé d'Yedo, et que ce personnage, dont la volonté toute puissante courbe les plus hautes têtes dans le royaume, a été le seul adversaire réel du traité que j'avais à conclure. " (Lettre de l'amiral Guérin au ministre de la Marine et des Colonies en date du 6 décembre 1855, Archives nationales, MAR BB/4/735, ff. 53-55).

35. Ryūkyū ökoku hyōjōsho monjo, op. cit., vol. 11, 1995 : 106, 152.

36. Côté ryūkyū, la convention est signée par le sōri daijin Shō Eiho (cf. supra) et les fusei taifu Ba Ryōsai 馬良才 (pseudonyme de Tanabaru uēkata Chōku 棚原親方朝矩) et Ō Tokuyū 翁徳裕 (pseudonyme de Shō Tokuyū ou Nomura uēkata Chōgi 野村親方朝 宜). Un exemplaire de la convention est conservé aux Archives nationales sous la cote MAR BB/4/735, ff. 56-57. 


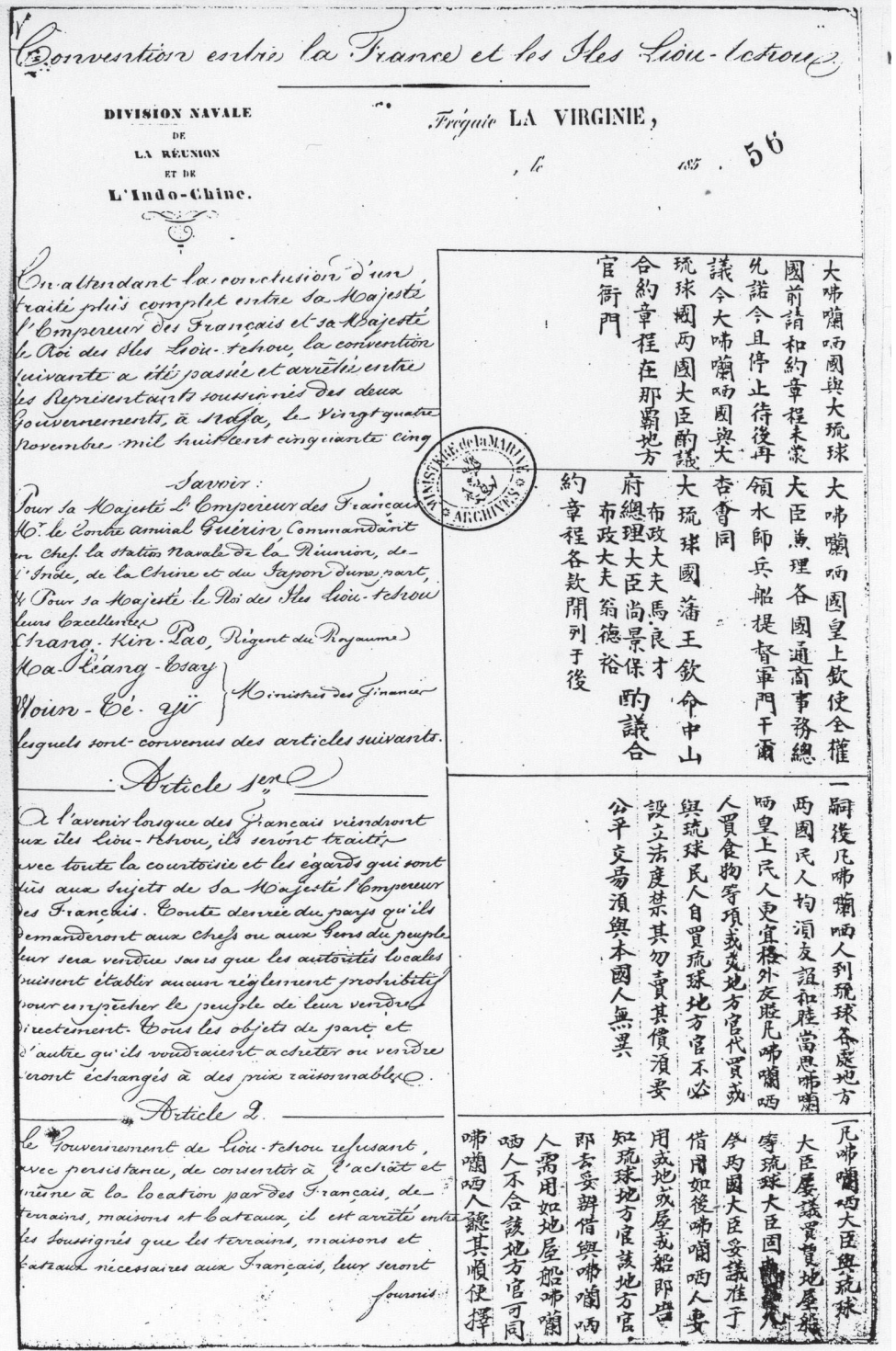

Fig. 7. Première page, sur quatre, de la convention conclue entre la France et le royaume des Ryūkyū le 24 novembre 1855 (Archives nationales). 
avec le Japon demeurait incertaine. L'ouverture du port de Naha pouvait alors apparaître comme étant "d'une grande importance pour le commerce européen " en cas de fermeture prolongée du Japon, ainsi que l'écrit Auguste Heurtier, délégué du ministère de l'Agriculture et du Commerce et membre de l'expédition ${ }^{37}$. La convention signée par l'amiral Guérin assura surtout aux missionnaires un meilleur traitement, notamment en leur permettant d'avoir bientôt leur propre maison entourée d'un grand jardin. Celle-ci, qu'ils tinrent à payer de leurs deniers, fut achevée de construire en janvier 1856 sur la colline Matsuo 松尾丘 dans le quartier de Kumemura 久米村, à un emplacement qu'ils avaient eux-mêmes choisis ${ }^{38}$.

\section{VI.}

Au total, avec la venue ultérieure de Pierre Mounicou et de Bernard Petitjean, cinq missionnaires vont séjourner en même temps ou successivement à Okinawa entre février 1855 et octobre 1862. À partir d'octobre 1856, après le retrait d'un second missionnaire britannique, E.H. Moreton, ils y furent les seuls résidents étrangers. Beaucoup d'événements survinrent durant ces sept années et demie, qu'il est impossible de résumer ici. C'est Louis Furet qui passa le plus de temps sur l'île, plus de six ans, de février 1855 à octobre 1862 , avec une absence de près d'un an et demi durant laquelle il participa à une expédition navale à Hokkaidō et en mer d'Okhotsk. Ses lettres sont d'un grand intérêt pour l'historien. Ancien professeur de mathématiques et

37. "Cette convention faite dans des conditions favorables avec un peuple primitif est d'un bon augure pour l'avenir de nos relations avec ce riche pays ", A. Heurtier, "Commerce avec le littoral japonais et les îles Liou-Tcheou, spécialement au point de vue des intérêts français - Iles Liou-Tcheou (19 août 1856) ", Annales du commerce extérieur (faits commerciaux 24), mars 1857 : 9-10. Dans les Nouvelles Annales de la Marine et des Colonies (tome 17, $1^{\text {er }}$ semestre $1857: 332$ ), Heurtier envisage la possibilité d'établir à Naha un "entrepôt de toutes les marchandises recherchées sur les marchés du Japon ». Dans la même revue, deux ans plus tard, un auteur anonyme croit pouvoir prédire à l'archipel Ryūkyū « un grand avenir » qui en fera " une des places les plus avantageuses que l'on puisse rencontrer pour le commerce dans les mers de l'Asie orientale » (ibid., tome $21,1^{\text {er }}$ semestre $1859: 139-140$ ).

38. Le plan de la maison est reproduit au début de Ryūkyū ōkoku hyōjōsho monjo, op. cit., vol. 14 . 
de sciences, médecin à l'occasion, il se plaisait à observer et à décrire tant les choses de la nature que les rapports que lui et ses confrères entretenaient avec les fonctionnaires et la population. Il fut aussi le correspondant de plusieurs sociétés savantes : la Société d'ethnographie du japonisant Léon de Rosny, qui publia plusieurs de ses lettres ${ }^{39}$, la Société d'acclimatation, à laquelle il envoya de nombreux spécimens ${ }^{40}$, et la Société météorologique de France, pour laquelle il procéda quotidiennement à des relevés.

Il vaut d'être noté que si la correspondance des missionnaires était souvent acheminée vers la Chine par des navires de passage, elle le fut aussi, depuis l'époque de Forcade, par les navires du royaume qui se rendaient une fois l'an à Fúzhōu 福州, soit pour transporter le tribut et l'ambassade ryūkyū, soit pour aller rechercher celle-ci, et dans l'une et l'autre circonstance pour y faire du commerce.

Comparées aux conditions de vie de leurs prédécesseurs, dix ans plus tôt, celles de Furet et de ses confrères s'améliorèrent sensiblement, notamment à partir de 1857 en raison de consignes émanant de Satsuma. Pour les aider dans l'étude des langues japonaise et chinoise, ils eurent jusqu'à neuf maîtres qui appartenaient, pour six d'entre eux, à l'académie de Shuri, créée à la fin du XVIII ${ }^{e}$ siècle, et, pour les trois autres, à celle traditionnelle de Kumemura, où résidait la communauté d'origine chinoise. Des livres leur furent fournis, et certains d'entre eux, tel Furet, purent véritablement commencer à se familiariser avec la culture et l'histoire japonaises, et même entreprendre des traductions. Leur liberté de mouvement était complète, bien que leurs faits et gestes restassent plus ou moins discrètement observés. Plus remarquable encore fut l'amélioration de leurs relations avec les représentants du gouvernement. Ceux-ci montrèrent tant de sollicitude à leur égard que Furet s'amuse à dénoncer dans ses lettres un système de supplices

39. Notamment, Lettres à M. Léon de Rosny sur l'archipel japonais et la Tartarie orientale, par le P. Furet missionnaire apostolique au Japon, membre correspondant de la Société d'ethnographie. Précédé d'une introduction par E. Cortambert et suivi d'un traité de philosophie japonaise et de plusieurs vocabulaires, Paris, Maisonneuve, 1860. Cette seconde édition des lettres de Furet à Rosny contient trois chapitres sur Okinawa et une " oraison dominicale" en langue ryūkyū.

40. Voir P. Fournier, Voyages et découvertes scientifiques des missionnaires naturalistes français à travers le monde pendant cinq siècles, $x v^{e} \dot{a} x x^{e}$ siècles, Paris, Paul Lechevalier, $1932: 124$. 
par la politesse et les douceurs. Mais les missionnaires eux-mêmes ne furent jamais avares de cadeaux afin de s'attirer les bonnes grâces des autorités. Parmi ces cadeaux figurent des kaléidoscopes, des montres de poche, un microscope et un télescope, des livres, une carabine, divers instruments de musique, jusqu’à un télégraphe électrique que Furet reçut de ses soutiens en France $^{41}$. Le roi lui-même se vit offrir une pendule. Tout cela, ou presque, profita évidemment à Satsuma. Pour autant, prêcher le christianisme leur restait interdit, bien qu'ils pussent parfois discuter avec des lettrés ou des officiers des mérites respectifs de leur religion et du confucianisme. Furet alla jusqu'à rédiger une apologie du christianisme à l'adresse du roi, sans trop s'illusionner sur la portée de son initiative.

\section{VII.}

L'événement le plus saillant de cette période est la démarche entreprise par le daimyō de Satsuma, Shimazu Nariakira, pour acheter un navire de guerre à la France. Nariakira, que les livres d'histoire ne manquent pas de présenter comme le précurseur de la politique de fukoku kyōhei 富国強兵, " pays riche, armée forte ", s'employa avec ardeur à introduire les sciences et techniques occidentales dans son fief. À Iso 磯, à la périphérie nord de Kagoshima, il créa un véritable complexe proto-industriel, le Shūseikan 集成館, à des fins à la fois militaires et commerciales. Du chantier naval de Sakura-jima 桜島 sortit dès 1852 un premier navire de type occidental, suivi de plusieurs autres dont la construction fut patronnée par le gouvernement d'Edo. Des problèmes subsistaient cependant, notamment pour la motorisation, et l'achat de navires aux Européens finit par apparaître comme la meilleure solution pour commencer à constituer une marine de guerre. En 1857, dans la crainte que les traités de commerce que les États-Unis et d'autres pays s'apprêtaient à signer avec Edo ne renforcent l'hégémonie shōgunale, Nariakira décida d'ouvrir son fief au commerce avec l'Occident selon un plan longuement mûri, esquissé dès 1846. Les Hollandais étant indécis, il se tourna vers la France qui avait manifesté son aspiration à commercer avec le Japon et dont trois ressortissants vivaient à Okinawa.

41. Mais les acides pour son fonctionnement firent défaut. 
Pour mettre en ouvre son plan, dont je laisse ici de côté les aspects relatifs à la Chine ou à Taiwan, Nariakira envoya à Okinawa, en novembre 1857, Ichiki Shirō 市来四郎, homme de confiance et spécialiste des armements formé à Nagasaki ${ }^{42}$. Celui-ci fut assisté par des officiers ryūkyū acquis aux vues de Nariakira, au premier rang desquels le fameux Itarashiki (ou Makishi) Chōchū 板良敷 (牧志) 朝忠 ${ }^{43}$ et le mono-bugyō 物奉行 (intendant général) Onga uēkata Chōkō 恩河親方朝恒. En quelques mois, il procéda à un vigoureux remaniement de l'exécutif du royaume afin de s'assurer de sa loyauté. En particulier, conformément aux ordres de Nariakira, il exigea l'éviction du sanshikan 三司官 ${ }^{44}$ Zakimi uékata Seifu 座喜味親方盛普 ${ }^{45}$ et fit ensuite nommer à sa place Onaga uēkata Chōchō 翁長親方朝長 qui avait obtenu le moins de voix - une seule - dans le vote organisé pour la circonstance. Le 31 mars 1858, vêtu et coiffé comme un officier ryūkyū, Ichiki Shirō prit contact avec les Français sous le faux nom d'Ichira pēchin 伊知 良親雲上 et en prétendant être un médecin de Tokara désireux de suivre des cours de français et de sciences. L'artifice ne trompa pas les Français. Très vite, lui-même ne cacha plus être un envoyé de Satsuma et il s'ouvrit à eux du but de sa mission. Les trois prêtres, qui virent là l'occasion de pouvoir enfin pénétrer au Japon, lui apportèrent sans ambages leur concours. En quatre mois une commande fut rédigée pour un "vapeur de guerre à

42. Vers la fin de sa vie, Ichiki Shirō (1828-1903) compila de nombreux documents concernant Shimazu Nariakira, par exemple ceux publiés sous le titre Shimazu Nariakira genkōroku 島津斉涁言行録 (Recueil des actes et paroles de Shimazu Nariakira), Tokyo, Iwanami bunko, 1995 (1944). Il est aussi connu pour être l'un des officiers qui prirent les premières photos japonaises, des daguerréotypes, dont celle, célèbre, de Shimazu Nariakira.

43. Son statut initial était celui d'interprète. Au contact des Européens, il avait acquis quelques notions d'anglais et il fut le principal intermédiaire avec les Américains durant la présence de l'escadre du commodore Perry à Okinawa, en 1853 et 1854 . Son portrait figure dans la relation de l'expédition américaine (Francis K. Hawks, Narrative of the Expedition of an American Squadron to the China Seas and Japan, Washington, 1856). Shimazu Nariakira récompensa son habileté et sa loyauté par de l'argent et des promotions successives qui en firent, en 1858, l'égal des uēkata et lui permirent de siéger au gouvernement parmi les omote-jyügonin 表十五人.

44. Nom de l'exécutif composé de trois ministres et titre donné à ceux-ci. Il se situait dans la hiérarchie du gouvernement après le roi et le régent.

45. Zakimi Seifu était sanshikan depuis 1847. Il lui était reproché sa mauvaise gestion des rapports avec les Américains et son hostilité aux projets d'ouverture de Shimazu Nariakira. 
hélice ", des armes et divers équipements, avec toutes les spécifications techniques et financières nécessaires. Initialement, Nariakira aurait souhaité acquérir deux navires, l'un de guerre, l'autre marchand, mais, par crainte de complications, on jugea préférable de s'en tenir au plus urgent, le navire de guerre. L'engagement prévoyait également l'invitation d'ingénieurs français et l'envoi d'étudiants de Satsuma et des Ryūkyū, déjà désignés, en France et, de là, dans d'autres pays occidentaux. Le nom de Satsuma n'apparaissait pas dans les documents. Officiellement, c'est le royaume des Ryūkyū qui se portait garant du paiement, la fiction de Tokara ne pouvant avoir de crédit auprès d'un État ou d'une société marchande.

Les documents n'attendaient plus que la venue d'un navire de la marine nationale, que l'on savait proche, lorsqu'arriva, le 8 octobre 1858, la nouvelle de la mort soudaine de Nariakira, survenue durant un exercice militaire préparatoire à une attaque contre Edo et le tairōo 大老 Ii Naosuke 井伊 直塥. Nariakira, sans enfant mâle, avait choisi pour successeur le jeune fils de son demi-frère et rival Shimazu Hisamitsu 島津久光, lequel devenait de fait le dirigeant de Satsuma. Hostile à la politique d'ouverture de Nariakira - mais il révisera vite sa position -, il ordonna l'annulation immédiate de la commande. Pour expliquer aux Français cet étrange revirement, on leur fit croire qu'Ichiki Shirō s'était tué en tombant de cheval. Un remplaçant viendrait, mais en attendant il leur fallait rendre les documents. Déçus et quelque peu sceptiques, ceux-ci se firent beaucoup prier, et ce n'est que le 20 octobre, cinq jours avant l'arrivée de l'aviso Le Prégent, qu'ils consentirent à s'en démettre après qu'on leur eut montré une tombe censée être celle d'Ichiki Shirō. Ce dernier, qui s'était aussitôt caché et qui songea d'abord à se suicider, pourra regagner Satsuma quelques mois plus tard et y exercer encore d'importantes fonctions. Mais ses soutiens locaux devront, eux, subir la cruelle vengeance des hommes qui avaient été écartés du pouvoir ${ }^{46}$.

Tous les missionnaires venus à Okinawa à partir de 1855 allèrent ensuite s'établir au Japon. Furet et Petitjean furent les derniers à quitter l'île, le 12 octobre 1862, à bord du Dupleix. À cette occasion, le gouvernement

46. Pour plus de détails sur la mission d'Ichiki Shirō à Okinawa, voir P. Beillevaire, "Accounting for Transient Hopes : The French Involvement in Shimazu Nariakira's Plan to Open Trade with the West in Ryūkyū ", International Journal of Okinawan Studies, vol. 1 (2), décembre 2010 : 53-83. 
d'Edo s'étant refusé à reconnaître sa souveraineté sur les îles Ryūkyū, le commandant Jean Massot fut chargé de s'assurer que la convention conclue par la France, quoique non ratifiée, restait valide, en particulier que les Français avaient le droit "d'y louer ou acquérir des terrains pour y bâtir des maisons ou des magasins ${ }^{47}$. Des rapports furent également rédigés sur la situation politique et les défenses militaires en prévision d'éventuelles représailles contre Satsuma et sa politique xénophobe. Malgré les protestations des missionnaires, six cents des neuf cents piastres qu'avait coûtées la construction de leur maison leur furent remboursées ${ }^{48}$.

VIII.

Le titre de cette conférence, "Présences françaises à Okinawa ", aurait pu également évoquer en regard une présence ryūkyū en France. En effet, lors de l'exposition universelle qui se tint à Paris en 1867, sur le Champ-deMars, Satsuma bénéficia d'une représentation distincte de celle du gouvernement d'Edo grâce à l'entregent de son chargé d'affaires en Europe, le comte Charles de Montblanc ${ }^{49}$. Pour rehausser le statut du daimyō de Satsuma en même temps que son propre rôle, celui-ci avait ajouté au titre de "prince de Satsuma " celui de " roi des Ryūkyū ", position que luimême se chargea de faire connaître à travers la grande presse. À l'occasion de l'exposition, il fit frapper une médaille dans le style de celle de la Légion d'honneur, destinée à être offerte à des personnalités du monde de la politique et des affaires, sur laquelle on peut lire les caractères 薩摩琉球国,

47. Archives du ministère des Affaires étrangères, correspondance politique, Japon, $\mathrm{n}^{\circ} 7$, septembre à décembre 1862, ff. 174-183, 248-272.

48. AMEP, vol. $569: 832-833$.

49. W. F. Vande Walle, "An Extraordinary Destiny : Count de Montblanc (18331894) ", Japan and Belgium. Four Centuries of Exchange, published by the Commissioners-General of the Belgian Government at the Universal Exposition of Aichi, 2005 : 140-157. 


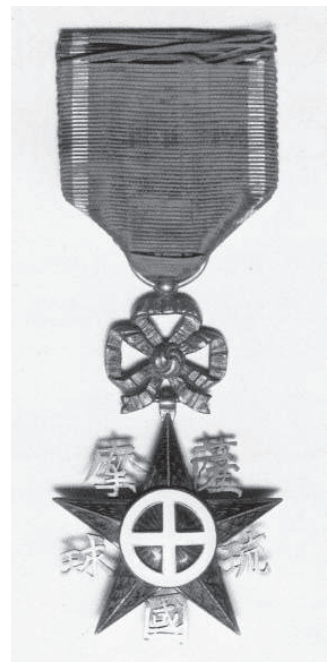

Fig. 8.

Médaille célébrant la présence de Satsuma et du royaume des Ryūkyū à I'Exposition universelle de Paris en 1867. Pour l'occasion, le titre de roi des Ryūkyū fut attribué au daimyō de Satsuma (Musée Reimeikan 黎明館, Kagoshima).

Satsuma Ryūkyū koku ${ }^{50}$ (fig. 8). Le plan de l'exposition montre du reste une allée de Liou-Kiou longeant les pavillons de Satsuma et de la Chine ${ }^{51}$.

On relève que dans la première édition du catalogue de l'exposition, où la seule "Principauté de Liou-Kiou " (traduction de 琉球国) semble représenter le Japon tout entier - Edo ne s'étant manifesté que tardivement -, figurent les noms, tous japonais, de sept artisans - orfevre, sculpteur, sellier, papetier, fabricant d'instruments de musique - prétendument domiciliés à Naha et même à Unten, bourgade où bien sûr aucun atelier de la sorte n'eût été trouvé ${ }^{52}$. Tous les autres artisans, domiciliés, eux, à Satsuma, sont

50. Voir Kagoshima kenshi 鹿児島県史 (Histoire du département de Kagoshima), Tokyo, Kondō shuppansha, vol. 3, 1980 (1939) : 227-234.

51. Commission impériale, Rapport sur l'exposition universelle de 1867 à Paris. Précis des opérations et liste des collaborateurs, Paris, Imprimerie impériale, 1869, planche II.

52. Exposition universelle de 1867 à Paris. Catalogue général publié par la commission impériale. Première partie (groupes I ̀̀ V), contenant les auvres d'art, et idem, deuxième

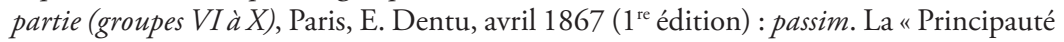
de Liou-Kiou " est représentée dans diverses classes des groupes I, II, III, IV, V et VII. Le nom d'Unten était toutefois supposément connu en France, car, comme on l'a vu, 
pareillement mentionnés, pour chaque classe de produits, sous l'enseigne de la "Principauté de Liou-Kiou » et à la suite des titres et noms d'apparat de leur daimyō : Son Altesse Matsudaira Shuri-no-daibu Minamoto no Mochihisa 松平修理大夫源茂久 ${ }^{53}$.

En novembre 1878, à la fin de la période appelée Ryūkyū shobun 琉球 処分, ou " mise au pas des Ryūkyū ”, quatre mois avant la création du département d'Okinawa, deux hauts dignitaires et sanshikan en fonction, Tomigawa uēkata Seikei 富川親方盛奎 et Yonabaru uēkata Ryōketsu 与那 原親方良傑, vinrent en personne remettre à la légation de France à Tokyo une pétition contre l'annexion de leur royaume par le Japon ${ }^{54}$. Évoquant les nombreux liens historiques et culturels qui unissent celui-ci à la Chine depuis le XIV siècle, mais aussi son annexion progressive par le Japon depuis six ans, elle fait appel à la France, "dans cette heure de péril imminent ", pour qu'elle enjoigne au Japon de se retirer du royaume. À l'appui de leur demande, les pétitionnaires prennent argument du traité conclu en 1855 par lequel la France reconnaissait les Ryūkyū comme une « nationalité distincte ". Le ministre français, De Geofroy, pour qui cette " affaire ne date pas d'hier ", et qui confesse n'avoir pu différer plus longtemps sa rencontre avec les deux envoyés, compatit sincèrement au sort des habitants de ces îles. Mais il n'envisage nullement d'entreprendre une démarche pour soutenir une cause qu'il sait vouée à l'échec et qui ne pourrait qu'offenser le gouvernement japonais ou rendre confuse la politique de la France : "Les bonnes gens de Liéou-Kiéou sont intéressants et leur cause est juste. Les Japonais les ont annexés impudemment et ont ensuite fait croire à tout le monde que la Chine avait consenti. [...] Mais ces patauds de Chinois méritent-ils qu'on prenne en main leur cause, et cela au moment où ils

c'est là que s'étaient déroulées les négociations de 1846. C'était aussi le lieu choisi par Shimazu Nariakira pour commercer avec les Européens.

53. Après une rencontre entre la délégation de Satsuma et celle du gouvernement d'Edo, le 21 avril, le daimyō de Satsuma fut plus simplement appelé, d'un commun accord, Satsuma taishu 薩摩太守 et Matsudaira Shuri-no-daibu.

54. Archives du ministère des Affaires étrangères, correspondance politique, Japon, 1877-1878, tome 26, ff. 394-399. Les deux officiels sont désignés par leurs vrais noms chinois (karanāa), respectivement Mō Hōrai 毛鳳来 et Ba Kensai 馬兼才, Mao Funglai et Ma Kientsai dans la traduction française de l'époque. 
nous inquiètent du côté du Tonkin ${ }^{55}$ ? ". Au reste, ce plaidoyer bien argumenté pour un retour au statu quo ante, c'est-à-dire à la double allégeance du royaume envers la Chine et le Japon considérés comme " mère " et " père ", témoignait d'un évident manque de réalisme au vu du principe de souveraineté territoriale qui désormais s’imposait aussi dans cette région du monde.

IX.

Des Français venus à Okinawa après le départ des missionnaires, et avant de parler de Charles Haguenauer, je n'en mentionnerai que quatre, qui ont chacun publié une relation de leur visite. D'abord, le commandant Henri Rieunier et l'enseigne de vaisseau Jules Revertegat qui font escale à Naha en mai 1877 à bord de La Clocheterie $^{56}$. Passé sous la coupe du Naimushō 内務省, le ministère de l'Intérieur, le royaume n'existe déjà plus qu'au titre désuet de han, ou " fief ". Invités au palais de Shuri, le commandant et sept officiers s'y rendent à pied depuis Naha escortés par un fonctionnaire subalterne du Naimushō qui, lui, fait le trajet en kago 駕籠 (palanquin). Le commissaire principal chargé de la liquidation du han des Ryūkyū, Matsuda Michiyuki 松田道之, était alors reparti à Tokyo. Au palais, ils ne peuvent rencontrer le roi, qui se dit souffrant, mais ils sont reçus par un discret vieillard, un mono-bugyō, qui est en retour invité le lendemain à bord du navire français.

Au milieu des années 1890, Joseph Ferrié, prêtre des Missions étrangères établi à Naze 名瀬, sur l'île d'Ōshima 大島, fait le voyage d'Okinawa pour voir les lieux où ont vécu ses confrères cinquante ans plus tôt. Si le Seigenji n'a guère changé, il a quelque peine à retrouver la tombe d'Adnet parmi vingt-et-une tombes d'étrangers, car l'inscription que Leturdu y

55. Ibid., ff. 362-384, 392-394, 400-401. La même tonalité critique à l'égard des mesures coercitives employées par le Japon se retrouve dans les articles parus dans Le Temps des 3 mai et 7 août 1879 .

56. Jules Revertegat, "Une visite aux îles Lou-Tchou, 1877 ", Le Tour du Monde, XLIV, 2 : 250-256, lithographies; extrait du journal d'Henri Rieunier, Hervé Bernard, «Visite d'un bâtiment de la marine française dans le petit royaume tropical des îles Ryūkyū en mai 1877 ", Neptunia, n 260, 2010 : 33-40, photographies. 
avait fait graver est à peu près effacée. Il se rend ensuite à Nago 名護 et dans la péninsule de Motobu, à l'invitation d'un chrétien qu'il a connu à Ōshima. La région est pauvre, les " habitants mal nourris ", les hommes " paresseux et ivrognes ", les femmes faisant « la majeure partie du travail nécessaire à l'entretien de la famille ». À Naha, ce qui le frappe «c'est le peu d'influence morale qu'exercent les Japonais sur les indigènes, surtout au point de vue de la langue ». Il a l'impression que « les habitants d'Okinawa s'obstinent à demeurer un peuple à part dans l'empire du Japon ». Sur les scènes de théâtre de Naha, on n'entend que «le dialecte du pays ». Dans le commerce, tandis que les Japonais s'attachent à apprendre la langue d'Okinawa, "leurs employés indigènes ne font aucun effort pour comprendre le japonais ${ }^{57}$.

Le quatrième visiteur français est le comte Maurice de Périgny, membre de la Société de géographie et de la Société franco-japonaise de Paris, qui s'arrête à Okinawa en juin 1905. Historien et ethnographe amateur, il retrace à grands traits le passé du royaume pour expliquer son annexion, et il en décrit certaines coutumes : tatouages des mains de femmes, mariage et funérailles. Il relève aussi les succès de la politique de développement mise en œuvre par Tokyo, en particulier dans les domaines de l'éducation scolaire et de la voierie. C'est la civilisation européenne qui s'implante maintenant dans ces îles, constate-t-il, tandis que le "pittoresque s'en va " : "Les derniers vestiges de l'ancien royaume de Riou-Kiou seront bientôt détruits. La race se transforme, les indigènes abandonnent leur langage, leur coiffure, leurs coutumes. Ils se japonisent. À l'instar de leurs conquérants, ils changent de civilisation, ils s'européanisent. " Il observe cependant que, " au contraire des femmes japonaises ", celles d'Okinawa " ont beaucoup d'autorité et [que] les hommes leur témoignent beaucoup de respect ${ }^{58}$.

Charles Haguenauer mériterait à lui seul une longue présentation. Éminent japonologue aux compétences étendues, professeur à la Sorbonne, il est le fondateur de l'Institut des hautes études japonaises du Collège de

57. "Aux Liou-Kiou ", Annales de la Société des missions étrangères et de l'auvre des partants, Paris, Missions étrangères, 1901 : 104-110, 142-146.

58. En courant le monde, Paris, Perrin, 1906 : 115-139 ; "Histoire d'une principauté japonaise : les îles Riou-Kiou ", À travers le monde, n 50, 10 décembre 1910 : 393395, photographies ; "Aux îles Riou-Kiou et en Corée ", Bulletin de la Société francojaponaise de Paris, XXV, mars 1912 : 95-107, photographies. 
France. C'est un peu le père des études japonaises en France, après le lointain ancêtre Léon de Rosny. Son intérêt pour Okinawa naît lorsqu'il est pensionnaire à la Maison franco-japonaise ${ }^{59}$. Le milieu des folkloristes japonais, dont il est proche, tend alors à considérer Okinawa comme un conservatoire de la culture du Japon antique. Il est notamment en relation avec le "père des études sur Okinawa ", Iha Fuyū 伊波普猷, natif d'Okinawa et membre du Nantō danwa-kai 南島談話会 (Groupe de discussion sur les îles du Sud) créé par Yanagita Kunio 柳田国男 en 1922. C’est en mars 1930 qu'il se rend à Okinawa pour y effectuer une enquête ethnographique et linguistique qui durera près de six semaines. Six semaines c'est court, mais cette recherche sur le terrain fut d'une particulière intensité, et le volume des informations collectées proprement impressionnant. Il est vrai qu'Haguenauer fut guidé par quelques-uns des meilleurs folkloristes ou historiens locaux. Il bénéficia aussi de l'appui de personnalités, parmi lesquelles le journaliste et maire de Shuri Ōta Chōfu 太田朝敷 et le quatrième fils du dernier roi, Shō Tai 尚泰, le baron et homme d'affaires Shō Jun 尚順, qui mit à sa disposition sa bibliothèque privée dans sa belle demeure de Shuri, près de l'étang Ryūtan 龍潭. Son enquête le mena dans de nombreux villages à travers toutes les régions de l'île, et même sur la petite île de Kudaka 久高島 où s'ancrent les mythes fondateurs de l'ancien royaume. Ses notes et croquis, dont la sûreté du trait révèle un talent de dessinateur, portent principalement sur les cycles cérémoniels, les rites de la naissance et de la mort, ou encore sur les fonctions religieuses et leur hiérarchie. Fin phonéticien, il étudia aussi les variations dialectales en comparant les vocabulaires de plus d'une vingtaine de localités. S'il ne s'attarde guère sur la situation politique, on trouve néanmoins éparses dans ses notes quelques observations sur la japonisation linguistique et culturelle, ou sur la répression de certaines coutumes, comme celle des mōashibi 毛遊び, ces rassemblements festifs de jeunes organisés à la tombée de la nuit et propices aux relations sexuelles.

L'intérêt d'Haguenauer pour Okinawa participait d'un grand projet de recherche sur les origines de la civilisation japonaise. Les matériaux qu'il en a rapportés n'ont toutefois donné lieu qu'à la publication de deux courts textes sur les rites funéraires, dans lesquels transparaît l'influence de Marcel

59. L'établissement venait d'être fondé par Paul Claudel et Shibusawa Eiichi 渋沢栄一. Haguenauer en fut le premier pensionnaire, de 1925 à 1932. 
Mauss dont il fut l'élève. Ses autres publications relatives à Okinawa - sur l'appellation Gores donnée par les Portugais ou sur la question du pays de Liuqiu dans le Suishū 隋書 - concernent des temps plus anciens et ne tirent que très peu parti de son enquête. La publication récente de ses notes de terrain permet d'en apprécier toute la richesse, ainsi que la valeur documentaire en regard du brutal chamboulement qu'allait connaître cette société quinze ans plus tard ${ }^{60}$.

Ici s'achève cet exposé sur l'histoire des rapports entre les Français et Okinawa, trop bref pour en présenter toutes les facettes. Il nous a conduits de l'époque du royaume à celle du département, de la discrète tutelle de Satsuma à celle assumée de Tokyo. La souveraineté du royaume des Ryūkyū pouvait n'être que virtuelle et la courtoisie de ses officiers une posture défensive dictée par la faiblesse, la conscience historique des habitants d'Okinawa fait aujourd'hui volontiers vertu, dans un contexte de relations ambivalentes avec le reste de la nation, de ce passé où leur île accueillait les Occidentaux alors que le Japon s'obstinait à les tenir à l'écart.

60. Okinawa 1930. Notes ethnographiques de Charles Haguenauer, éditées et commentées par P. Beillevaire, Paris, Collège de France, Institut des hautes études japonaises, 2010 . 